\title{
Opioids Disrupt Pro-Nociceptive Modulation Mediated by Raphe Magnus
}

\author{
Kevin M. Hellman ${ }^{1,2,3}$ and Peggy Mason ${ }^{1}$ \\ Departments of ${ }^{1}$ Neurobiology, and ${ }^{2}$ Obstetrics and Gynecology, University of Chicago, Chicago, Illinois 60637, and ${ }^{3}$ NorthShore University HealthSystem, \\ Evanston, Illinois 60201
}

In anesthetized rats, opioid analgesia is accompanied by a specific pattern of tonic activity in two neuronal populations within the medullary raphe magnus (RM): opioids silence pain-facilitatory $\mathrm{ON}$ cells and produce sustained discharge in pain-inhibitory $\mathrm{OFF}$ cells. These tonic activity patterns, hypothesized to generate a tonic analgesic state, have not been observed in recordings made without anesthesia. Therefore, we recorded $\mathrm{ON}$ and $\mathrm{OFF}$ cell activity before and after an analgesic dose of morphine in unanesthetized mice. The tonic activity of $\mathrm{ON}$ and OFF cells was unchanged by morphine. Rather, morphine suppressed the phasic ON cell excitation and OFF cell inhibition evoked by noxious stimulation. Before morphine, the magnitude of the noxious stimulus-evoked burst in ON cells correlated with motor withdrawal magnitude, suggesting that $\mathrm{ON}$ cells facilitate nocifensive motor reactions. Contrary to model prediction, $\mathrm{OFF}$ cell activity was greater before stimulus trials that evoked withdrawals than those without withdrawals. Since withdrawals only occurred when OFF cell activity was suppressed, a decrease in OFF cell activity appears to serve as a pro-nociceptive signal that synchronizes and therefore strengthens the ensuing motor reaction. We further propose that morphine acts in RM to suppress ON and OFF cell phasic responses and thereby disable RM's pro-nociceptive output. Thus, RM cells produce antinociception by failing to exert the pronociceptive effects normally engaged by noxious stimulation. These findings revise the conventional understanding of supraspinal opioid analgesia and demonstrate that RM produces on demand rather than state modulation, allowing RM cells to serve other functions during pain-free periods.

\section{Introduction}

The revolutionary discoveries of stimulation-produced analgesia (Reynolds, 1969) and endogenous opioids (Pert and Snyder, 1973) bore the field of endogenous pain modulation, resulting in the characterization of descending nociceptive modulatory pathways that synapse in raphe magnus (RM). Neurons within RM are the final common pathway for nociceptive modulatory influences on the spinal cord arising from many brainstem and forebrain areas. RM neurons project to superficial laminae of the dorsal horn (Brodal et al., 1960; Dahlstroem and Fuxe, 1964) and stimulation of RM results in direct inhibition of nociceptive dorsal horn neurons (Fields et al., 1977; Gebhart et al., 1983). RM is an important contributor to systemic opioid analgesia (Dickenson et al., 1979; Azami et al., 1982) and is necessary for supraspinal opioid analgesia (Gilbert and Franklin, 2002).

Current understanding of the neurophysiology of pain modulation, based entirely on recordings from anesthetized rats, holds that tonic activity in a population of RM neurons, OFF cells, suppresses pain and produces analgesia (Fields et

Received March 23, 2012; revised July 27, 2012; accepted Aug. 1, 2012.

Author contributions: K.M.H. and P.M. designed research; K.M.H. performed research; K.M.H. and P.M. analyzed data; K.M.H. and P.M. wrote the paper.

This research was supported by NIH Grant R21DA022429. K.M.H. was supported by the American Academy of Sleep Medicine Faculty Career Advancement Award.

Correspondence should be addressed to Peggy Mason, Department of Neurobiology, University of Chicago, MC 0928, 947 East 58th Street, Chicago, IL 60637. E-mail: p-mason@uchicago.edu.

DOI:10.1523/JNEUROSCI.1551-12.2012

Copyright $\odot 2012$ the authors $\quad 0270-6474 / 12 / 3213668-11 \$ 15.00 / 0$ al., 1983b). Tonic activity in an opposing cell population, $\mathrm{ON}$ cells, is thought to produce a state of hyperalgesia (Heinricher et al., 1989; Porreca et al., 2002). Tonic excitation of OFF cells and inhibition of $\mathrm{ON}$ cells in response to various opioids administered by different routes techniques are consistent, often replicated, findings in anesthetized rats (Toda, 1982; Heinricher and Rosenfeld, 1985; Barbaro et al., 1986; Fang et al., 1989; Heinricher et al., 1992, 1994; Brink et al., 2006; Hellman et al., 2007). However, a single study in the unanesthetized rat did not observe any change in tonic ON cell activity in response to morphine as is observed in anesthetized rats (Martin et al., 1992). This singular study reported that in response to morphine, the tonic activity of ON-like cells did not change. These results, reported almost 2 decades ago, raise serious concerns about the currently accepted model of RM pain modulation.

To test whether tonic changes in discharge within RM modulate nociception, we recorded the responses of RM cells to noxious stimulation before and after an analgesic dose of morphine. Importantly, all recordings were made in unanesthetized animals, a technically challenging approach but the one that is most appropriate to the study of nociception.

\section{Materials and Methods}

All animal care and experiments were in accordance with the National Institutes of Health guidelines and approved by the Institutional Animal Care and Use Committee of the University of Chicago.

Male C57BL/6 mice (12-16 weeks old; Charles River) were used for all experiments. Mice were housed under standard colony conditions. 
Habituation. All habituation and recording experiments were performed in a laboratory environment during the light cycle. Animals were returned to the animal colony after habituation and recording sessions. Habituation was initiated by handling over a $3 \mathrm{~d}$ period. After habituation to handling, mice were acclimated to being securely wrapped in an $8 \times 8 \mathrm{~cm}$ (length $\times$ circumference), soft, cotton-lined tube with Velcro on the outside for short periods of time $(1 \mathrm{~min})$. Mice were placed in the Velcro wrap daily for increasing amounts of time until they were comfortable and did not struggle. Over a period of 2 weeks, mice adapted to being wrapped and fell asleep shortly after being placed in the tube. In this way, mice learned to tolerate the tube holder for up to $3 \mathrm{~h}$. While in the tube, animals were given water every 30-45 min and occasionally were treated to chocolate hazelnut spread. Weight was monitored daily throughout the study, and animals that did not maintain their weight were excluded from further study.

Surgery. Anesthesia was induced with $5 \%$ isoflurane and maintained at $2 \%$ isoflurane in room air. Core temperature was maintained with a water-perfused heating pad. Sterile EEG screws, EKG leads, and EMG wires in the hindlimb flexors were inserted, secured with VetBond (3M), and routed to a single in-line pin socket that was subsequently cemented to the skull with Cerebond Adhesive (Plastics One). A $2 \mathrm{~mm}$ diameter craniotomy was centered $1.5 \mathrm{~mm}$ caudal to lambda to allow for placement of a stainless steel base which was then covered. Polyethylene tubing [inside diameter (ID), $0.28 \mathrm{~mm}$ ] was implanted subcutaneously and secured with glue. The tubing was externalized near the pin connector and melted shut. Prosthetic nylon guide tubes ( $20 \mathrm{~mm}$ long; $4 \mathrm{~mm}$ ID; 6 $\mathrm{mm}$ outside diameter) were glued to the assembly to permit future stabilization of the head. Immediately and $12 \mathrm{~h}$ after surgery, animals were given buprenorphine $(0.1 \mathrm{mg} / \mathrm{kg}$, s.c. $)$ as an analgesic.

Habituation to head restraint. After 1 week of recovery from surgery, animals were rehabituated to restraint and then prepared for head restraint within a custom stereotaxic device. A model 1430 David Kopf Instruments stereotaxic device and a model 880 chronic recording attachment apparatus were modified for mice. The stereotaxic device was equipped with a model 1760 -SB micro-manipulator for vertical manipulation of a recording electrode. The stereotaxic apparatus held four interlocking stainless steel pins that could be inserted into two prosthetic nylon tubes attached to the animal, allowing for repeated head restraint and stereotaxically guided unit recordings in unanesthetized mice.

After 2-3 d of reacclimation to the Velcro tube, the stereotaxic pins were inserted into the nylon guide tubes atop the animal's head but were not screwed in securely. This loosely kept the mouse, wrapped in the tube, within the stereotaxic apparatus and resulted in moderate restriction of head movements. In the ensuing sessions, the pins were gradually secured more and more tightly, and the mouse remained in the stereotaxic apparatus for increasing amounts of time. Animals were given water and chocolate hazelnut spread every 30-45 min. Mice that failed to rapidly fall asleep within six sessions were not used further.

Setup for recording sessions. Once animals demonstrated the ability to tolerate $3 \mathrm{~h}$ of head restraint within the stereotaxic apparatus, electrophysiological recording sessions began. A piezoelectrode microphone was placed on the mouse thorax to record breathing. The left hindpaw was placed on a Peltier device and loosely secured with Velcro so that animals could remove their paw in response to heat stimulation trials. In between trials, the paw was returned to the Peltier device with the heat turned off. After the craniotomy cover was removed, the dural surface was rinsed with $1 \%$ lidocaine and punctured with a bent electrode. A single tungsten metal electrode (5 M $\Omega$, A-M Systems) was lowered vertically into the region of RM (1.5-2.5 mm posterior from lambda, 0.0$0.25 \mathrm{~mm}$ lateral from lambda, $5.0-6.0 \mathrm{~mm}$ ventral from cerebellar surface). Single-unit activity was amplified 10,000 times with a DP3-304 Warner Instruments amplifier. Unit waveforms were acquired at $40 \mathrm{kHz}$ by a CED Micro1401 interface. Single-unit activity was sorted off-line in Spike2 (version 7) with a template-matching algorithm.

The electrode was lowered until unit activity was detected. Once one or more single units were isolated, $1000 \mathrm{~s}$ of unstimulated baseline activity was acquired. After baseline activity was recorded, a $5 \mathrm{~s}, 49^{\circ} \mathrm{C}$ heat stimulus was applied to the hindpaw using a Peltier device; this stimulus was repeated two to five more times with a $500 \mathrm{~s}$ interstimulus interval until cell type was clear. Only stable units that were clearly excited or inhibited on at least two of three trials were studied; with these criteria, only $25 \%$ of isolated units were chosen for study.

Following the final premorphine heat trial, $1 \mathrm{mg}$ of morphine sulfate (dissolved in $0.1 \mathrm{ml}$ of PBS; Mallinckrodt) was injected via the implanted subcutaneous line. Then, $500 \mathrm{~s}$ after injection, three more trials of heat stimulation were applied as above. The recording location of every cell recorded in response to morphine was marked by passing $20 \mu \mathrm{A}$ anodal current through the recording electrode for $4 \mathrm{~min}$. The animal was then overdosed with $5 \%$ isoflurane and perfused with a fixative containing $10 \%$ formalin in 0.1 м PBS.

Of 218 extracellular units initially isolated, 22 neurons were successfully recorded for the entire protocol and histologically verified to be in RM. Data for these 22 cells were analyzed and are presented.

Analysis. RM cells are classified as ON or OFF cells based on neuronal responses to noxious stimulus trials that evoke a motor withdrawal (Fields et al., 1983a). Because only neurons that were consistently excited or inhibited by heat were studied and because animals withdrew from noxious heat in most premorphine trials, all neurons were easily classified as ON (excited by heat) or OFF (inhibited by heat) cells. Neuronal responses during stimulus trials that failed to evoke a withdrawal (this occurred infrequently before morphine and consistently afterward) were compared with those during responding trials. Thus, for each neuronal class ( $\mathrm{ON}$ or $\mathrm{OFF}$ ), each trial subcategory (responding, nonresponding) and each condition (before and after morphine), peristimulus histograms of neural activity from $30 \mathrm{~s}$ before to $30 \mathrm{~s}$ after the stimulus onset were computed using $250 \mathrm{~ms}$ bins. Each bin was calculated as a moving average of the current bin and the previous three bins. An ANOVA with Bonferroni's correction for multiple comparisons identified poststimulus bins that were significantly different $(p<0.05)$ from pretrial activity. This process was repeated for the dataset after morphine. Stimuluslocked histograms were generated by aligning cell discharge to the start of the heat stimulus (Fig. 1).

We normalized cell discharge for use in (1) response-locked histograms and (2) regressions with withdrawal characteristics. In brief, we applied a $z$-score (or standard score) normalization using the mean and SD of the discharge (spikes within $250 \mathrm{~ms}$ bins) from the entire length of the premorphine recording. Thus, the $z$-score reflects the number of SDs separating cell activity in any one $250 \mathrm{~ms}$ bin from the mean of all premorphine $250 \mathrm{~ms}$ bins. In addition, we calculated an evoked $z$-score by subtracting the average $z$-score during the $30 \mathrm{~s}$ ( 120 bins) preceding each heat application from the $z$-score for each bin after heat onset. Responselocked histograms were then generated by aligning the evoked $z$-score to either the onset (see Fig. 3) or climax (Fig. 2) of the EMG response. Using an ANOVA and Bonferroni's correction for multiple comparisons, bins that were significantly different from pretrial activity were identified. Finally, the maximal EMG response was regressed on the average evoked $z$-score for the preclimax period ( $1 \mathrm{~s}$ or 4 bins before EMG climax; see Figs. $2 C, 4 B, 7 E, F)$. This particular time period was chosen because preliminary analyses showed that the correlation between cell firing and peak EMG magnitude was strongest for cell discharge during this period.

To analyze withdrawal magnitude, the EMG recording was full-wave rectified. We then defined withdrawal onset as the earliest time point when the EMG value exceeded the average pretrial EMG value by $\geq 1 \mathrm{SD}$. Note that the pretrial period included spontaneous movements and consequently the SD of the EMG was large. To compare withdrawal magnitudes across animals, we then applied $z$-score normalization to EMG activity. Finally, the EMG climax was determined as the maximum in the integrated EMG record.

To determine the effects of morphine on tonic RM discharge, the average firing rate for each neuron was computed for $500 \mathrm{~s}$ before and after morphine administration. During these periods, no stimulation was applied. An ANOVA was used to compare average discharge rates before and after morphine for ON and OFF cells. To assess the regularity of discharge, the coefficient of variation of the interspike interval (ISI) and entropy were calculated. The former was calculated from interspike intervals recorded during the unstimulated $500 \mathrm{~s}$ periods immediately before and after morphine administration. Entropy was calculated [methods were adapted from Pogosyan et al. (2006)] for each neuron 
before and after morphine administration. In brief, logarithmic histograms of interspike intervals were convolved with a Gaussian kernel to construct a smoothed probability mass distribution function for each neuron. Shannon's equation (Shannon and Weaver, 1949) was then used to calculate entropy $(S)$ before and after morphine, as follows:

$$
S=-\sum_{i=0}^{n} p\left(x_{i}\right) \log _{2} p\left(x_{i}\right)
$$

where $p\left(x_{i}\right)$ is the probability distribution function (Pogosyan et al., 2006).

To determine the effects of morphine on heat-evoked discharge, the average neural activity for each neuron and for each trial was calculated by subtracting $10 \mathrm{~s}$ of pretrial activity from $10 \mathrm{~s}$ of activity after stimulus presentation. An ANOVA was performed to compare evoked RM discharge before and after morphine for ON and OFF cells.

To determine whether RM cell discharge changed across sleep/wake states, periods ( $\geq 15$ s) of non-REM sleep and of wakefulness were identified for each recording using standard criteria applied to EEG and nuchal EMG activity (Hellman et al., 2010). The activity of neurons during each state was compared with an ANOVA.

Histology. After perfusion, the brainstem was removed, post-fixed for $24 \mathrm{~h}$, and then immersed in $30 \%$ sucrose in $0.1 \mathrm{~m}$ PBS. Coronal sections $(25 \mu \mathrm{m})$ were cut on a cryostat. Sections were mounted on charged slides and then stained with cresyl violet. Recording sites were identified and assigned an anterior-posterior location and then plotted on standard sections adapted from Figure 2 of VanderHorst and Ulfhake (2006). We consider the murine RM to include a region $600 \mu \mathrm{m}$ wide centered on the midline that stretches from the medullary ventrum to a point $1000 \mu \mathrm{m}$ dorsal to the base of the brain. The rostral and caudal borders of RM are the first section caudal to the nucleus of the trapezoid body and the first section rostral to nucleus ambiguus, respectively.

\section{Results}

\section{$\mathrm{ON}$ and OFF cells in RM were recorded in} unanesthetized mice

A total of 22 units within RM were isolated and recorded from 18 mice before and after morphine administration. Recording sites were concentrated at the level of the facial nucleus $(-6.0 \mathrm{~mm}$ from bregma), but were extended rostrally to the level of the ascending facial rootlets $(-5.5 \mathrm{~mm})$ and caudally $(-6.5 \mathrm{~mm})$. Most $(n=14)$ cells were on or near the midline $(0.0-0.25 \mathrm{~mm}$ from midline), while the remaining eight cells were located at the lateral boundary of RM ( $>0.25 \mathrm{~mm}$ from midline).

Cells were classified as ON ( $n=12$ from 11 mice; $55 \%)$ or OFF ( $n=10$ from 9 mice; $45 \%$ ) by their response to noxious tail or paw heat. Isolated units with characteristics of neutral or serotonergic cells (Mason, 1997) were intentionally not studied. The tonic discharge rates of $\mathrm{ON}$ and OFF cells during wakefulness averaged $51 \pm 13$ and $25 \pm 7$ spikes/s, respectively.

$\mathrm{ON}$ and OFF cells were identified by their consistent excitatory and inhibitory responses, respectively, to noxious thermal stimulation that elicited a withdrawal (Fields et al., 1983a; Leung and Mason, 1998). Figure 1 shows the average responses of all ON
B

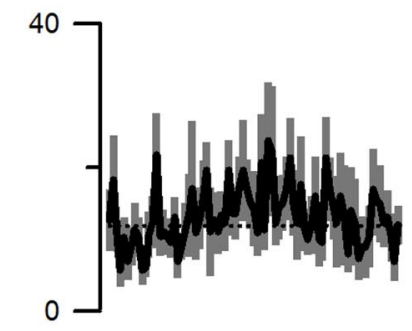

E

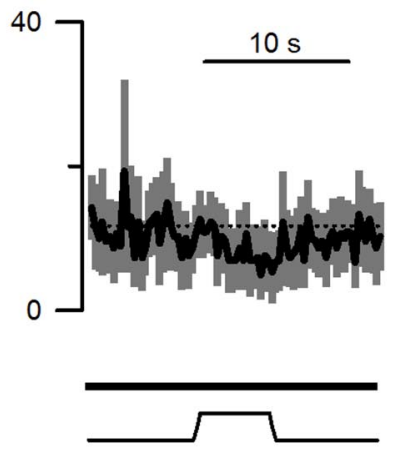

C

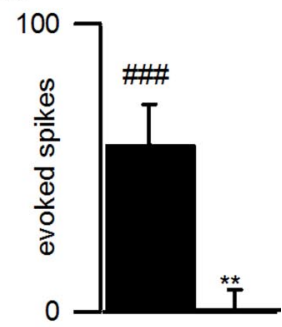

$\mathbf{F}$

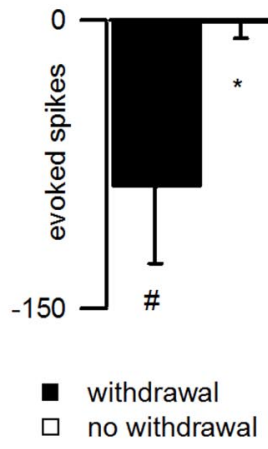

Figure 1. RM ON and OFF cells responded to noxious stimulation when a withdrawal motor reaction occurred. $A, B, D, E$, Data are presented from 18 animals for the average firing rate ( $250 \mathrm{~ms}$ bins) from $0 \mathrm{~N}(\boldsymbol{A}, \boldsymbol{B})$ and $0 \mathrm{FF}$ cells $(\boldsymbol{D}, \boldsymbol{E})$ in heat trials that either elicited a withdrawal ( $\boldsymbol{A}$ shows data from 25 trials on $120 \mathrm{~N}$ cells in 11 mice; $\boldsymbol{D}$ shows data from 22 trials, 10 OFF cells, 9 mice) or aver $<0.05$, difference between evoked activity and pretrial activity. ${ }^{* *} p<0.01,{ }^{*} p<0.05$, difference between evoked activity in

Fig. $1 A$ ) and OFF (Fig. 1D) cells for trials in which a withdrawal occurred (numbers of trials, cells, and mice are detailed in the Fig. 1 legend). As $\mathrm{ON}$ and OFF cells did not respond to noxious heat when a withdrawal was not elicited (Fig. $1 B, C, E, F)$, the ON cell burst $\left(t_{(27)}=3.6, p<0.01\right)$ and OFF cell inhibition $\left(t_{(27)}=2.3\right.$, $p<0.05)$ were larger in responding trials.

\section{The phasic responses of $\mathrm{ON}$ and OFF cells to noxious} stimulation shape and time the motor withdrawal Visual inspection of ON cell responses to individual stimulation trials revealed that the envelope of $\mathrm{ON}$ cell activity resembled the rectified EMG response after a short time lag (Fig. 2A). To quantitatively analyze this relationship, the normalized evoked activity (see Materials and Methods) of ON cells was aligned to the occurrence of the EMG climax, the time point of the largest recruitment of full wave-rectified motor activity (Fig. $2 B$ ). ON cell activity was elevated just before withdrawal onset and peaked just before the EMG climax. The evoked $z$-score during the $1 \mathrm{~s}$ period preceding the EMG climax was correlated with maximal EMG magnitude $\left(r^{2}=0.50 ; t_{(23)}=4.8 ; p<0.001\right.$; Fig. $\left.2 C\right)$. During this restricted period, there were trials in which cells fired at a rate below that of the average pretrial discharge. Since the evoked $z$-score is the change in $z$-score with respect to pretrial discharge (see Materials and Methods), the evoked $z$-scores for these trials were negative. Negative $z$-scores were always associated with a much reduced motor response. These results show that noxious stimulation elicits an ON cell burst in advance of the peak of the motor withdrawal, suggesting that $\mathrm{ON}$ cell activity produces a just-in-time facilitation of withdrawal magnitude. 

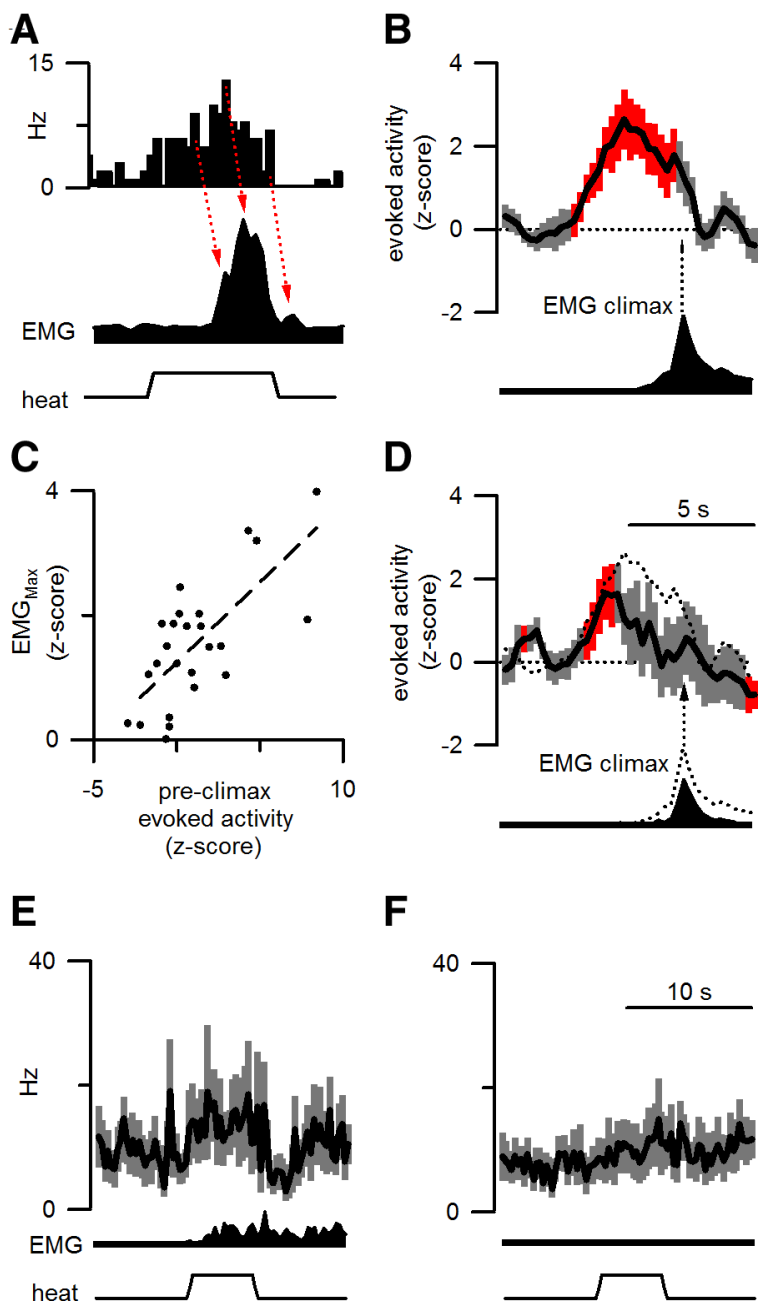

Figure 2. The responses of $0 \mathrm{~N}$ cells to noxious stimulation predict withdrawal amplitude. $\boldsymbol{A}$, The response to noxious stimulation of a representative $0 \mathrm{~N}$ cell peaked before local peaks in EMG activity (red arrows). $\boldsymbol{B}$, When plotted with reference to the start of the EMG climax (arrow), normalized $0 \mathrm{~N}$ cell activity ( 25 responding trials from $120 \mathrm{~N}$ cells in 11 mice) significantly exceeded pretrial discharge levels (red, $p<0.05$ after Bonferroni's correction for multiple comparisons) before EMG climax. C, ON cell activity during the preclimactic period reliably predicted the normalized peak withdrawal magnitude. $\boldsymbol{D}$, The normalized discharge and average EMG response during responding trials after morphine are plotted as in $\boldsymbol{B}$. The mean cellular and motor responses before morphine are represented by the dotted lines. Data include 17 responding trials from $100 \mathrm{~N}$ cells recorded from 9 mice. The time scale in $\boldsymbol{D}$ applies to $\boldsymbol{A}$ and $\boldsymbol{B}$ as well. $\boldsymbol{E}, \boldsymbol{F}$, The average firing rate ( $250 \mathrm{~ms}$ bins), after morphine administration, from $120 \mathrm{~N}$ cells is plotted for heat trials that either elicited a withdrawal (17 trials from 10 cells in 9 mice, $\boldsymbol{E}$ ) or failed to elicit a withdrawal ( 19 trials from 10 cells in 9 mice, $\boldsymbol{F}$ ). As in Figure 1, the average EMG response and applied heat stimulation are shown in the lower traces. The time scale in $\boldsymbol{F}$ also applies to $\boldsymbol{E}$.

The current model of RM modulation holds that elevated tonic OFF cell activity produces a state of low nociceptive responsiveness (Heinricher et al., 1989). Contrary to this model, OFF cell activity during the prestimulus period was higher before responding trials than before nonresponding trials in unanesthetized mice $\left(t_{(25)}=2.8, p<0.01\right.$; Fig. 1 , compare $D$, E, prestimulus activity levels). As OFF cells always paused in response to noxious stimulation that elicited a withdrawal, withdrawals were most likely to happen in trials when OFF cells were more active before the noxious stimulus application and then were silenced by the noxious stimulus. Since OFF cell discharge before a stimulus increases the likelihood of a withdrawal and since withdrawals only happen when OFF cells pause, a decrease in OFF cell activity,
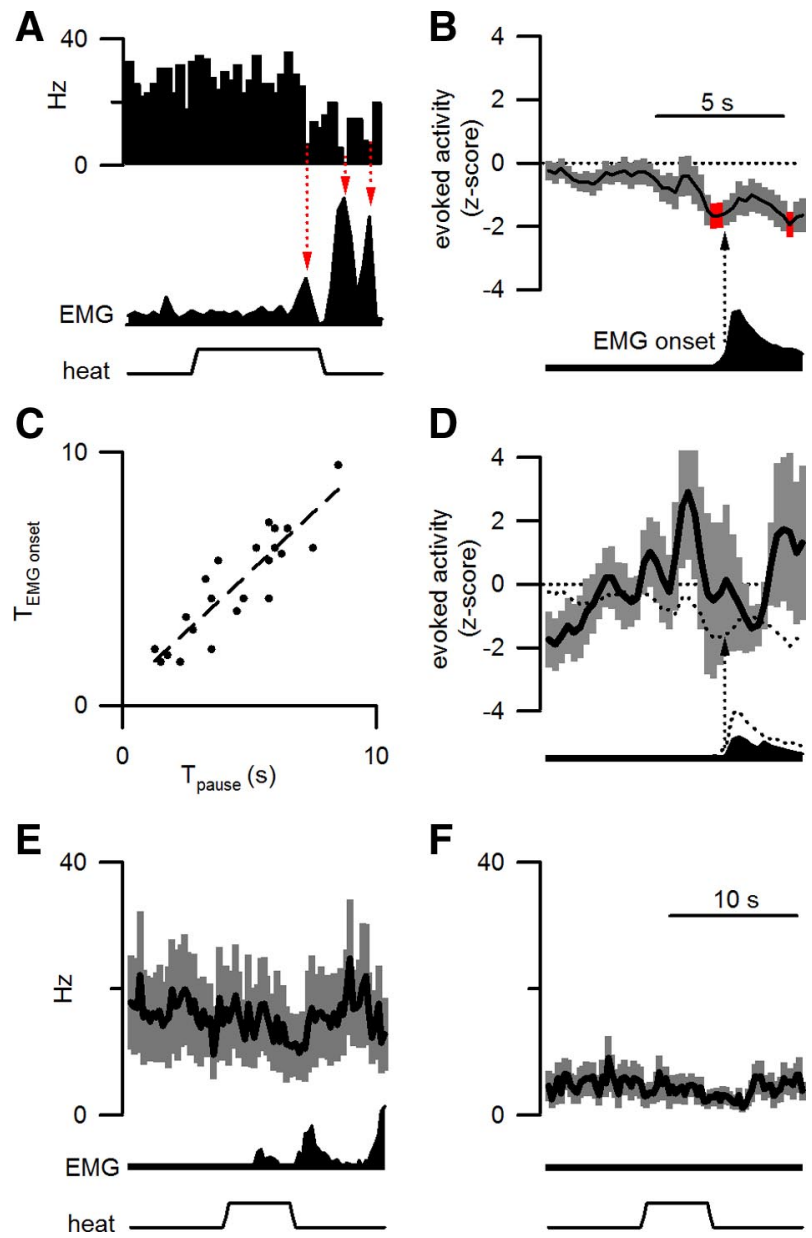

Figure 3. The evoked inhibition of OFF cells was time locked to the motor reaction and predicted withdrawal onset. $\boldsymbol{A}$, For a representative OFF cell, discharge decreased at times corresponding to local peaks in EMG activity (red arrows). $\boldsymbol{B}$, When aligned to the EMG climax (arrow), normalized OFF cell discharge (22 responding trials from 10 OFF cells in 9 mice) was significantly decreased (red) just before the withdrawal onset. The time scale illustrated in $\boldsymbol{B}$ also applies to $\boldsymbol{A}$ and $\boldsymbol{D}$. $\boldsymbol{C}$, The latency to withdrawal onset ( $\left.T_{\text {EMGonset }}\right)$ was correlated to the onset of the OFF cell pause ( $\left.T_{\text {pause }}\right)$. $\boldsymbol{D}$, The normalized discharge and average EMG response during responding trials after morphine are plotted as in $\boldsymbol{B}$. The mean cellular and motor responses before morphine are represented by the dotted lines. Data include 15 responding trials from $80 \mathrm{FF}$ cells recorded from 7 mice. $\boldsymbol{E}, \boldsymbol{F}$, The average firing rate $(250 \mathrm{~ms}$ bins) of $0 \mathrm{FF}$ cells is plotted for heat trials after morphine administration that either elicited a withdrawal ( 15 trials from 8 cells in 7 mice, $\boldsymbol{E}$ ) or failed to elicit a withdrawal ( 15 trials from 7 cells in 6 mice, $\boldsymbol{F}$ ). As in Figure 1, the average EMG response and applied heat stimulus are shown in the lower traces. The time scale in $\boldsymbol{F}$ also applies to $\boldsymbol{E}$.

rather than a lack of OFF cell activity, is key to OFF cell modulation. It is notable that ON cell activity during the prestimulus period was not different before responding and nonresponding trials $\left(t_{(14)}=1.2 ; p=0.26\right)$.

Visual inspection of individual stimulation trials suggested that pauses in OFF cell activity immediately precede local peaks in EMG activity (Fig. $3 A$ ). When aligned to withdrawal initiation, a brief and significant trough in OFF cell activity occurred just before withdrawal onset (Fig. 3B). To examine the temporal relationship between decreases in OFF cell activity and withdrawal onset, we measured the times from stimulus onset to (1) OFF cell pause and (2) the evoked withdrawal. We observed a direct correlation between the latencies to the pause and to withdrawal onset $\left(r^{2}=0.79 ; t_{(20)}=8.7 ; p<0.001\right.$; Fig. $\left.3 C\right)$, suggesting that the OFF cell pause may synchronize motor recruitment in spinal circuits. A similar, but weaker, correlation was observed between 


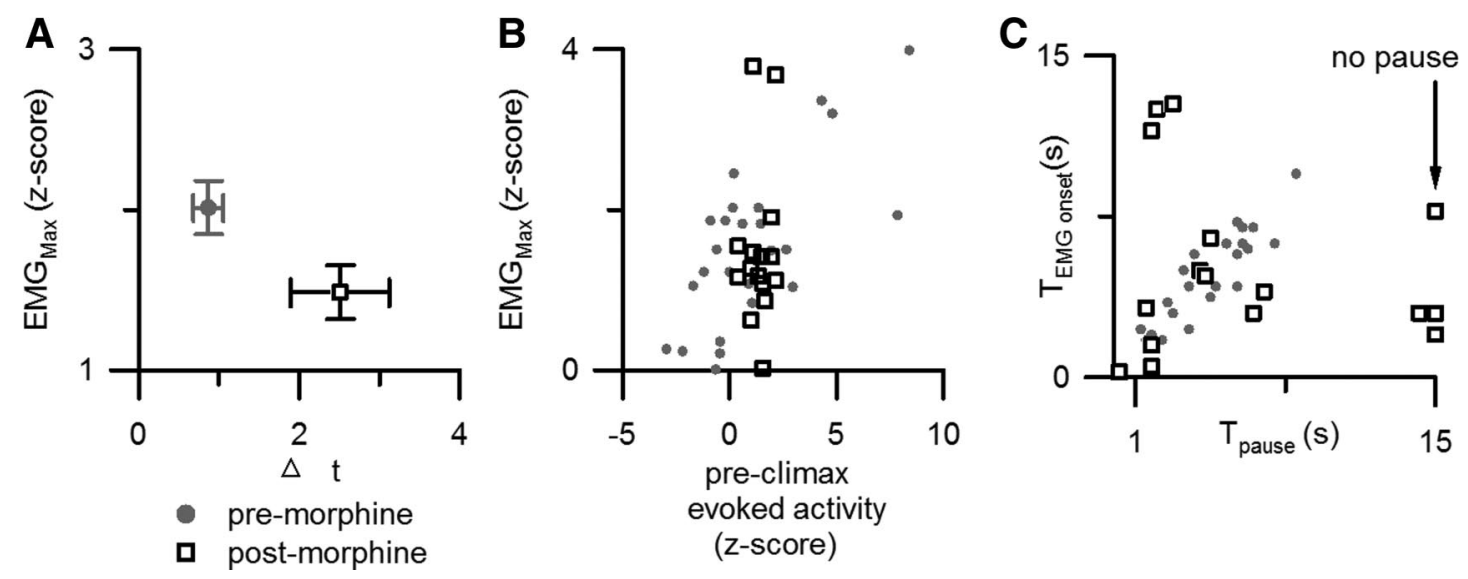

Figure 4. Morphine altered withdrawals and disrupted the relationship between $\mathrm{RM}$ cell responses and motor responses. $A$, The maximal withdrawal magnitude $\left(\mathrm{EMG}_{\mathrm{Max}}\right)$ and rise time $(\Delta t)$ before morphine administration (54 trials from 18 mice) are compared with values after morphine ( 54 trials from 18 mice). Morphine reduced withdrawal magnitude and increased the time between withdrawal onset and climax. B, Morphine disrupted the correlation between $\mathrm{ON}$ cell preclimactic discharge and withdrawal magnitude normally observed during premorphine conditions (gray circles, premorphine; black squares, postmorphine). All trials that evoked a motor response were analyzed (premorphine, 25 trials from $120 \mathrm{~N}$ cells in 11 mice; postmorphine, 17 trials from $100 \mathrm{~N}$ cells in 9 mice). $\boldsymbol{C}$, Morphine also disrupted the association between the onset of the OFF cell pause $\left(T_{\text {pause }}\right)$, and the time of withdrawal onset $\left(T_{\text {EMGonset }}\right)$ (symbols are as in $\left.\boldsymbol{B}\right)$. All trials that evoked a withdrawal were analyzed (premorphine, 22 trials from $10 \mathrm{OFF}$ cells in 9 mice; postmorphine, 15 trials from $80 \mathrm{FF}$ cells in 7 mice). Three trials without an $0 \mathrm{FF}$ cell pause are represented by symbols at the cutoff time of $15 \mathrm{~s}$.

the latencies to the $\mathrm{ON}$ cell burst and to withdrawal onset $\left(r^{2}=\right.$ $\left.0.37 ; t_{(23)}=3.6 ; p<0.001\right)$.

\section{Morphine administration produces antinociception without any change in the tonic activity of $\mathrm{ON}$ or OFF cells}

Administration of an analgesic dose of morphine (1 mg, s.c.) decreased the proportion of heat trials that elicited a withdrawal (before morphine, 39/54 trials; after morphine, 27/54; $\chi^{2}=5.6$; $p<0.05$ ) and reduced withdrawal maximal amplitude (paired $t_{(17)}=2.8 ; p<0.01$; Fig. $4 A$ ) but had no significant effect on the rate of ON or OFF cell tonic discharge $\left(\mathrm{ON}\right.$ : paired $t_{(11)}=1.4 ; p=$ 0.18 ; OFF: paired $t_{(9)}=1.1 ; p=0.30$; Fig. 5). Moreover, two measures of discharge regularity were not changed by morphine administration. First, the coefficient of variation of the interspike interval was not significantly different after morphine for either cell type (ON cells: before, $4.1 \pm 0.7$; after, $3.8 \pm 0.7$; paired $t_{(11)}$ $=0.5 ; p=0.66$; OFF cells: before, $4.4 \pm 0.7$; after, $4.9 \pm 0.9$; paired $\left.t_{(9)}=0.4 ; p=0.69\right)$. Second, average entropy was not significantly different before and after morphine for either ON cells (before, $4.5 \pm 0.2 \mathrm{bits} / \mathrm{spike;}$ after, $4.5 \pm 0.1 \mathrm{bits} / \mathrm{spike}$; paired $t_{(11)}=0.3 ; p=0.77$ ) or OFF cells (before, $4.6 \pm 0.1$ bits/spike; after, $\left.4.5 \pm 0.1 \mathrm{bits} / \mathrm{spike;} \mathrm{paired} t_{(9)}=0.6 ; p=0.57\right)$. These findings are strong evidence that, contrary to conclusions drawn from studies in anesthetized rat, the tonic activity of $\mathrm{ON}$ and OFF cells is not critical to opioid antinociception. Instead, as described below, morphine blocks the phasic responses of RM $\mathrm{ON}$ and OFF cells to noxious stimulation (Fig. 5).

\section{After morphine administration, $\mathrm{ON}$ and OFF cells are less responsive to noxious stimulation}

Although morphine exerted no effect on the tonic firing of $\mathrm{ON}$ cells, it reduced the phasic burst in ON cell discharge (Fig. $5 B, C, E$ ) and the phasic decrease in OFF cell discharge (Fig. $5 G, H, J)$ evoked by noxious stimulation. These reductions in response magnitude occurred regardless of whether responding (Figs. $2 E, 3 E$ ), nonresponding (Figs. $2 F, 3 F$ ), or all trials (Fig. $5 E, J)$ were analyzed.

Across the population of $\mathrm{ON}$ cells, the average response to noxious stimulation decreased from $44.1 \pm 16.9$ to $-1.2 \pm 11.1$ evoked spikes (paired $t_{(11)}=3.7 ; p<0.01$ ). Further analysis of individual cell responses to noxious stimulation before and after morphine revealed that four ON cells remained excited by noxious stimulation after morphine (Fig. 5E; Table 1). The remaining ON cells were either unaffected $(n=7)$ or inhibited $(n=1)$ by noxious stimulation after morphine. In most of the latter cases (six unaffected, one inhibited), noxious stimulation did not evoke a withdrawal in most postmorphine trials.

Before morphine, ON cell discharge during the $1 \mathrm{~s}$ period before EMG climax was strongly correlated with withdrawal magnitude. However, no such correlation was observed after morphine administration (Fig. 4B). The most parsimonious explanation for these results is that whereas normally ON cell activity greatly facilitates withdrawals, in the presence of morphine, ON cells are not excited by noxious stimulation and no facilitation occurs. As a consequence, after morphine, noxious stimulusevoked withdrawals are smaller in magnitude or absent.

Across the population of OFF cells, the average response to noxious stimulation decreased in magnitude from $-47.4 \pm 13.0$ to $-7.3 \pm 7.4$ evoked spikes (paired $t_{(9)}=3.3$; $p<0.01$ ). When analyzed individually, three OFF cells remained inhibited by noxious stimulation, whereas the remaining seven OFF cells were unaffected by noxious stimulation after morphine (Fig. 5J; Table 1). After morphine administration, OFF cell firing rates were again highest before heat trials that evoked withdrawals $\left(t_{(14)}=\right.$ $2.3 ; p<0.05)$, as was true during premorphine conditions. While brief pauses in discharge occurred in response to noxious heat in some cells, they did not occur at a consistent latency across cells. Therefore, discharge across the OFF cell population was not significantly altered by noxious heat applied after morphine administration (Fig. 5F-J).

To determine whether OFF cell discharge impacts withdrawal onset after morphine as it does before morphine, we compared the timing of the OFF cell pause (the first ISI that was at least 2 SDs greater than the mean ISI during the $10 \mathrm{~s}$ before the stimulus onset) to that of withdrawal onset. After morphine, there was no longer a consistent temporal relationship between the latencies to the pause of individual OFF cells and the onset of the concurrent withdrawal $\left(r^{2}=0.03 ; t_{(15)}=0.65 ; p=0.73\right.$; Fig. $\left.4 C\right)$. We hy- 
A

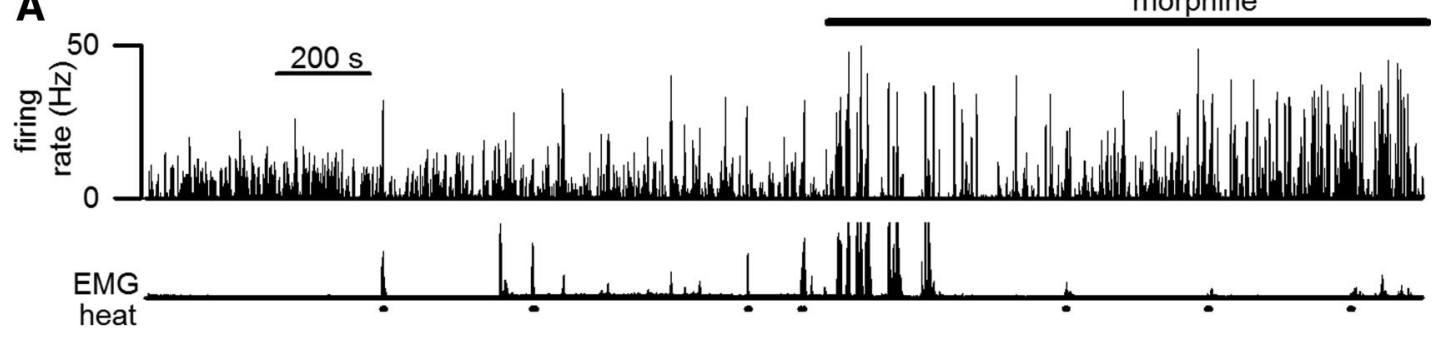

B

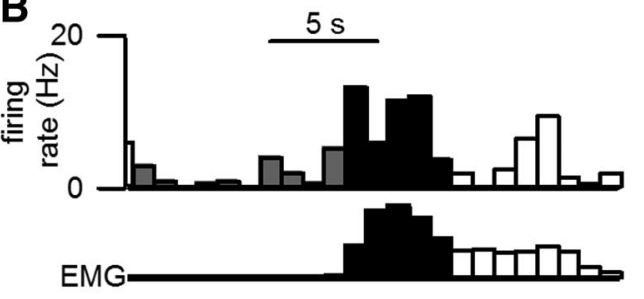

D

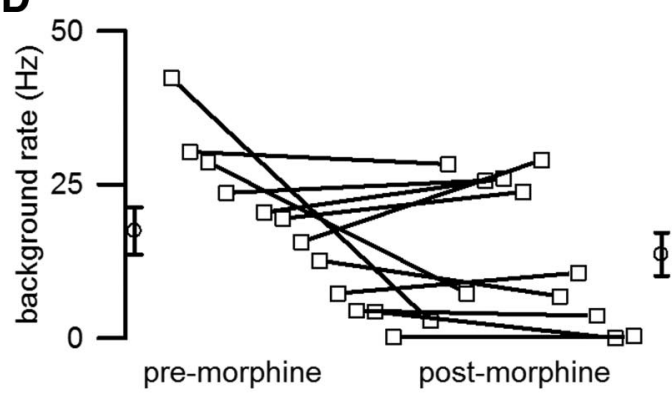

$\mathbf{F}$

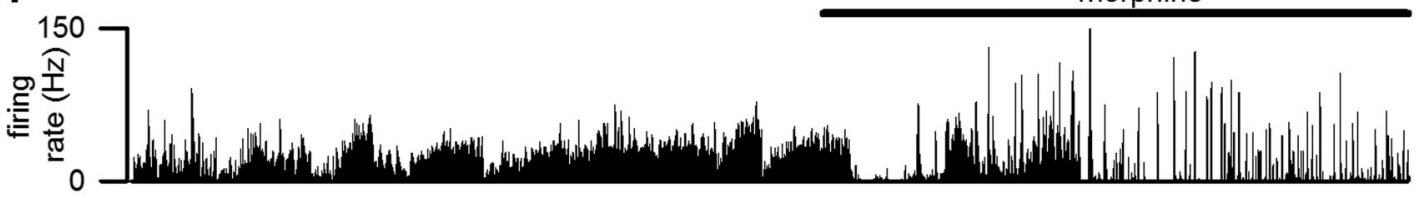

C

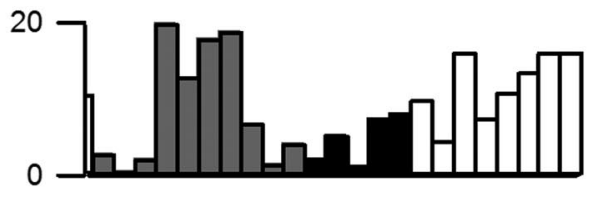

E

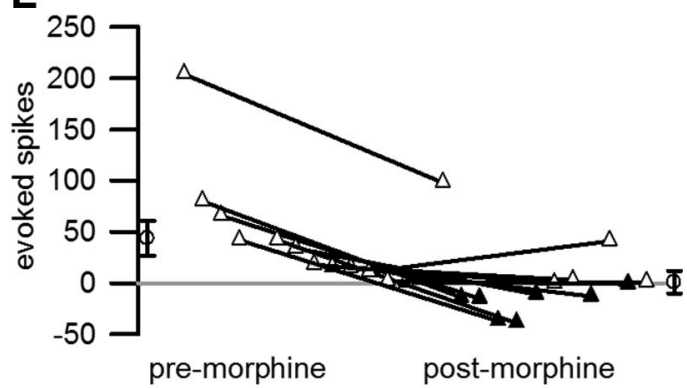

morphine
G

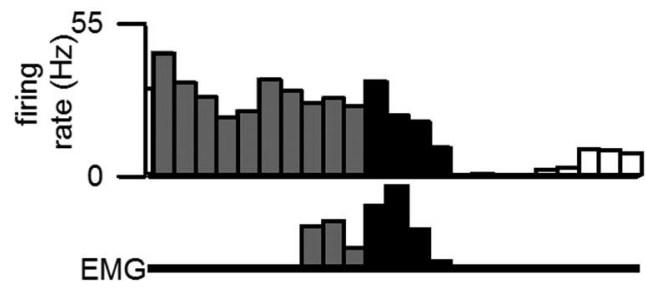

I

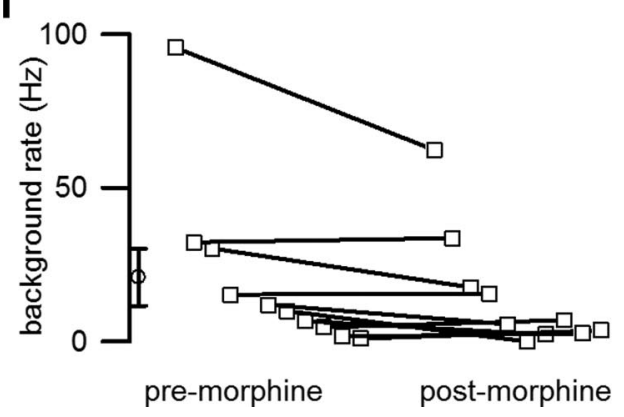

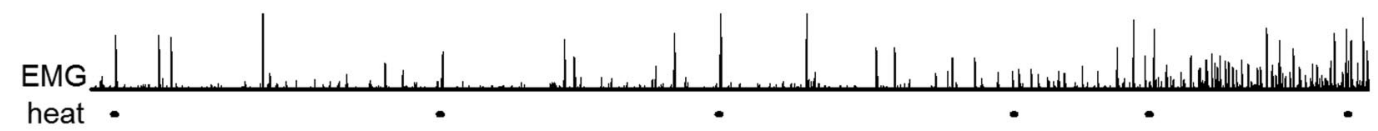

H
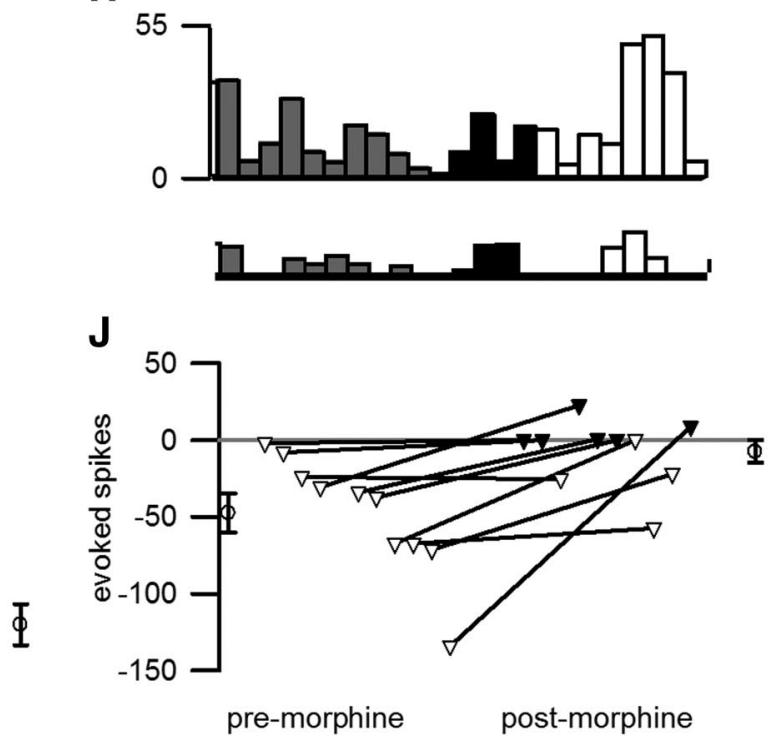

Figure 5. Morphine significantly reduced the responses of $\mathrm{ON}$ and $\mathrm{OFF}$ cells to noxious stimulation, but had no significant effect on tonic discharge rate. $\boldsymbol{A}-\boldsymbol{C}, \boldsymbol{F}-\boldsymbol{H}$, Cell discharge before and after morphine (spikes/s, $1 \mathrm{~s}$ bins) from representative ON $(\boldsymbol{A}-\boldsymbol{C})$ and $\mathrm{OFF}(\boldsymbol{F}-\boldsymbol{H})$ cells is shown. Cellular discharge (top trace) and EMG activity (bottom trace) (Figure legend continues.) 
pothesize that in abolishing the OFF cell pause, morphine prevents the pro-nociceptive synchronization of spinal circuits, resulting in a temporally dispersed motor withdrawal and a lower peak amplitude. Consistent with this prediction, after morphine the rise time between withdrawal onset and climax was greater (paired $t_{(17)}=2.7 ; p<0.05$ ), while the EMG magnitude was reduced $\left(\right.$ paired $t_{(17)}=2.8 ; p<0.05$; Fig. $4 A$ ).

\section{The discharge of $\mathrm{ON}$ and OFF cells changes across sleep and wake states}

Tonic RM cell discharge was different during sleep and wake states (Fig. 6), with OFF cells firing at higher rates during slowwave sleep (paired $t_{(9)}=2.3 ; p<0.05$ ) and $\mathrm{ON}$ cells firing at higher rates during wakefulness (paired $t_{(11)}=3.9 ; p<0.01$ ) as previously reported for rat (Leung and Mason, 1999). These results serve as a positive control for tonic changes in RM cell activity and further support our finding that morphine does not produce changes in tonic discharge.

Despite the greater tonic activity of OFF cells and reduced firing of ON cells during sleep, withdrawals were more reliably elicited during sleep than during wakefulness $\left(\chi^{2}=5.3 ; p<\right.$ $0.05)$. Accompanying the greater nociceptive responsiveness during sleep than wakefulness were greater phasic responses to noxious stimulation for OFF cells during sleep than during wakefulness (sleep: $-145 \pm 86$ spikes; $n=10$ trials from 9 cells; wakefulness: $-16 \pm 14$ spikes; $n=20$ trials from 10 cells). This difference was significant $\left(t_{(28)}=2.2 ; p<0.05\right)$. The ON cell burst was $54 \pm 32$ spikes during sleep ( $n=8$ trials from 6 cells) and $31 \pm 13$ spikes during wakefulness $(n=28$ trials from 12 cells), a difference that was not significant. While contrary to the predictions from the conventional model, this result fits well with our proposal that the magnitude of the OFF cell pause is positively related to the likelihood of an ensuing withdrawal.

\section{Morphine also suppresses the phasic responses of RM cells to noxious stimulation in anesthetized rats}

We compared our findings in the unanesthetized mouse to previously collected data gathered in the lightly anesthetized rat and using a different mode of opioid administration (Hellman et al., 2007). Rather than administer morphine subcutaneously as in the present study, we administered DAMGO intracerebroventricularly to anesthetized rats in the previous study. Under baseline conditions in the anesthetized rat preparation, noxious stimulation nearly always elicited a withdrawal (71/72), so much so that before opioid administration, trials without a withdrawal $(n=1)$ were insufficient in number to permit analysis. DAMGO administration decreased the proportion of heat trials that elicited a withdrawal (65\% from 99\%; $\chi^{2}=27 ; p<0.001$ ), and consequently responding and nonresponding trials post-DAMGO could be compared.

Confirming many previous reports (see Introduction), tonic $\mathrm{ON}$ and OFF cell discharge was altered by opioid administration

\footnotetext{
$\leftarrow$

(Figure legend continued.) are shown during unstimulated periods and in response to heat stimulation (lines beneath EMG trace). Cells showed significant responses to noxious heat before morphine administration $(\boldsymbol{B}, \boldsymbol{G})$ but not after morphine $(\boldsymbol{C}, \boldsymbol{H})$. The time scale in $\boldsymbol{A}$ applies to $\boldsymbol{A}$ and $\boldsymbol{F}$, and that in $\boldsymbol{B}$ applies to $\boldsymbol{B}, \boldsymbol{C}, \boldsymbol{G}$, and $\boldsymbol{H} . \boldsymbol{D}, \boldsymbol{E}, \boldsymbol{I}, \boldsymbol{J}$, For the population of $120 \mathrm{~N}(\boldsymbol{D}, \boldsymbol{E})$ and 10 OFF $(I, J)$ cells recorded from 18 mice, the average tonic discharge was not affected by morphine $(\boldsymbol{D}, \boldsymbol{I})$ but the evoked discharge was significantly reduced $(\boldsymbol{E}, \boldsymbol{J})$. The averages of all values premorphine and postmorphine are shown by the open circles to the left and right, respectively, of the lines. $\boldsymbol{E}, \boldsymbol{J}$, Open triangles mark cases when a withdrawal was evoked in a majority of the trials analyzed whereas filled symbols mark cases when a withdrawal was not evoked in most trials.
}

Table 1. The response to noxious stimulation after morphine administration is listed for all ON and OFF cells tested

\begin{tabular}{|c|c|c|c|}
\hline & \multicolumn{3}{|c|}{ Postmorphine response to noxious stimulation } \\
\hline & Inhibition & Inhibition & Excitation \\
\hline \multicolumn{4}{|c|}{ Cell type } \\
\hline ON & 1 (1) & $7(6)$ & $4(0)$ \\
\hline OFF & $3(0)$ & $7(6)$ & - \\
\hline
\end{tabular}

(DAMGO, $50 \mathrm{ng}$, i.c.v.) in the lightly anesthetized rat (Fig. 7A). Tonic ON cell discharge decreased (paired $t_{(16)}=4.5 ; p<0.01$ ) and tonic OFF cell discharge increased (paired $t_{(8)}=3.1 ; p<$ 0.05; Fig. 7A). In addition, alterations in evoked discharge were also observed (Fig. 7B). After DAMGO administration, ON cell bursts were only evoked when a withdrawal occurred (Fig. 7C). Whereas there was no relationship between pretrial normalized ON cell firing rate and EMG magnitude $\left(r^{2}=0.03 ; t_{(49)}=1.3\right.$; $p=0.10$; Fig. $7 D$ ), the relationship between evoked ON cell discharge (in the $1 \mathrm{~s}$ before climax) and EMG magnitude was significant $\left(r^{2}=0.13 ; t_{(49)}=2.7 ; p<0.01\right.$; Fig. $\left.7 E\right)$; this relationship persisted after DAMGO administration $\left(r^{2}=0.34 ; t_{(49)}=5.0\right.$; $p<0.001$; Fig. $7 F$ ).

As for ON cells, pretrial normalized OFF cell discharge was not predictive of withdrawal latency in the anesthetized rat $\left(r^{2}=\right.$ $0.14 ; t_{(19)}=1.7 ; p=0.09$; Fig. $\left.7 G\right)$. Yet, the timing of the OFF cell pause predicted withdrawal latency under baseline, premorphine conditions $\left(r^{2}=0.54 ; t_{(19)}=4.7 ; p<0.001\right.$; Fig. $\left.7 H\right)$. This relationship was not significant after intracerebroventricular DAMGO administration in anesthetized rats $\left(r^{2}=0.12 ; t_{(19)}=\right.$ 1.6; $p=0.06$; Fig. $7 I$ ). These findings support the idea that the noxious stimulus-evoked responses of $\mathrm{ON}$ and OFF cells are suppressed by opioids in the lightly anesthetized rat as well as in the unanesthetized mouse. In the absence of RM cell-driven facilitation and synchronization of spinal circuits, withdrawals are greatly attenuated.

\section{Discussion}

Specific patterns of tonic RM cell firing, including that elicited by opioids, are currently thought to produce tonic states of nociceptive responsiveness. However, we found that morphine does not alter the tonic firing rates of RM ON and OFF cells in unanesthetized mice. Since suppression of the phasic responses of RM cells to noxious stimulation accompanies withdrawal suppression, it is the suppression of phasic cellular responses that mediates RM antinociception. Our findings confirm results obtained from $\mathrm{ON}$ cells in awake rats and reported 20 years ago, and extend our understanding to include the responses of OFF cells to morphine in an unanesthetized preparation (Martin et al., 1992). Moreover, we propose a unified model that connects the activity recorded from RM cells in unanesthetized and anesthetized rodents alike to nociceptive reactions. Our model posits that during normal conditions (in the absence of analgesics), phasic responses to noxious stimulation of OFF and ON cells synchronize and facilitate motor withdrawals, respectively. Morphine then acts in RM to produce antinociception by suppressing cell responses to noxious stimulation, effectively disengaging RM-mediated facilitation of spinal circuits activated by noxious stimulation.

\section{The tonic discharge of $\mathrm{ON}$ and OFF cells is not altered by morphine in unanesthetized animals}

Morphine did not change the average tonic firing rate of RM cells recorded in the absence of anesthesia, consistent with a study that 
A
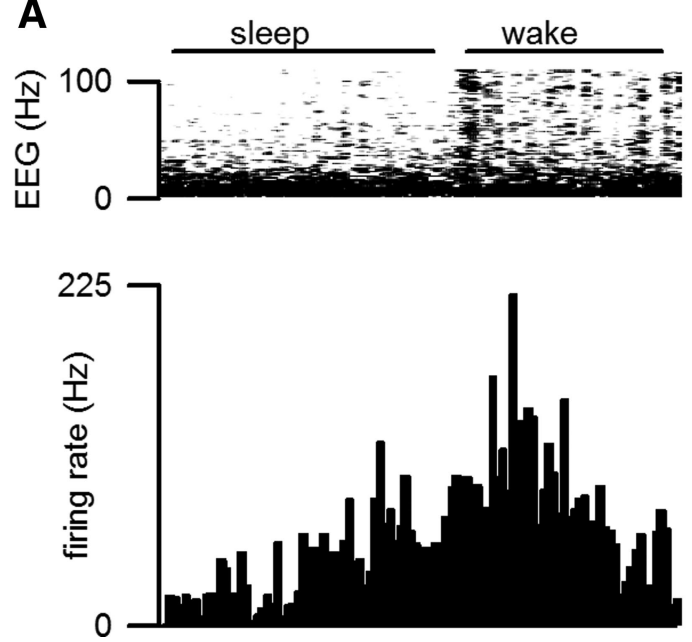

B
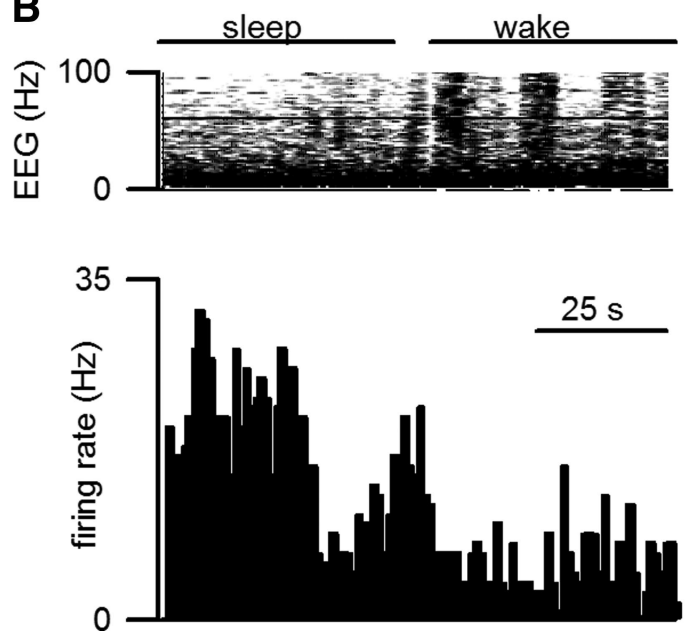

C

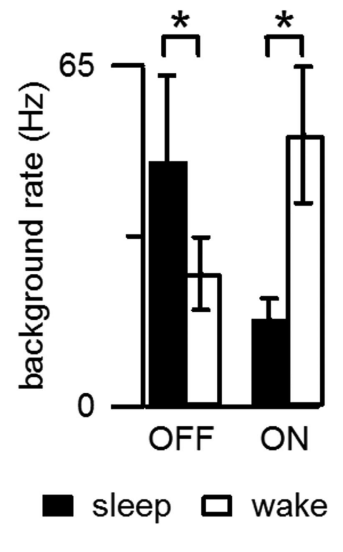

Figure 6. Tonic RM cell activity and nociceptive responsiveness were modulated by sleep/wake state. $\boldsymbol{A}, \boldsymbol{B}$, The tonic firing (lower graph) of a representative $0 \mathrm{~N}$ cell (A) was greater during wakefulness than during sleep whereas the tonic firing rate of a representative OFF cell $(\boldsymbol{B})$ was greater during sleep than during wakefulness. Sleep/wake state is indicated by EEG spectral activity (top graph). C, The tonic discharge rate of 10 OFF cells was greater during sleep than wakefulness and the reverse was true for the population of $120 \mathrm{~N}$ cells ( $n=18$ mice). ${ }^{*}$ Indicates a significant $(p<0.05)$ difference in the firing rate during sleep and wakefulness.

showed morphine had no effect on the spontaneous discharge of RM ON cells in awake rats (Martin et al., 1992). As Martin et al. (1992) did not isolate or record from any OFF cells, their conclusions concerned ON cells exclusively. A different group administered a high dose of morphine to unanesthetized rats and recorded the background discharge of RM units that were not characterized by their response to somatic stimulation (McGaraughty et al., 1993). The background discharge of 12 of 20 neurons increased and that of 8 neurons decreased in response to systemic morphine. Two major differences may account for the different results obtained. First, the cell types recorded by $\mathrm{McGa}$ raughty et al. (1993) are unclear. Second, McGaraughty et al. (1993) used a high dose of morphine, which elicits behavioral changes in awake animals (da Silva and Rocha e Silva, 1971; Chaillet et al., 1983; Winters et al., 1988). Since state changes alter the tonic firing of ON and OFF cells (Leung and Mason, 1999), the behavioral state changes evoked by morphine may have secondarily altered the tonic discharge of RM ON and OFF cells. The anesthetized state is not uniform, and state changes during general anesthesia influence the tonic discharge of rat $\mathrm{ON}$ and OFF cells (Grahn and Heller, 1989; Leung and Mason, 1995; Jinks et al., 2004); this may account for the changes in ON and OFF cell activity elicited by morphine in the anesthetized rat (Gao et al., 1998; Hellman et al., 2007).

In sum, our data suggest that the tonic discharge of $\mathrm{ON}$ and OFF cells does not mediate antinociception. One could view our finding that tonic OFF cell discharge just before a noxious event influences the likelihood of an ensuing motor reaction as an exception to this conclusion. However, the tonic discharge of an OFF cell only influences withdrawal likelihood insomuch as it allows for a smaller or larger phasic decrease in OFF cell discharge. Thus, no independent measure of ON or OFF cell tonic discharge is related to nociception in the unanesthetized mouse.

Whereas the tonic activity of $\mathrm{ON}$ and OFF cells changes across the sleep-wake cycle, our data do not support a role for such changes in the modulation of nociception. Tonic ON and OFF cell activity may modulate homeostatic functions beyond nociception, most if not all of which change across the sleep-wake cycle (Mason, 2005a,b).
Phasic RM responses mediate nociceptive modulation

As morphine does not elicit tonic changes in RM cellular discharge, the challenge is to understand how phasic but not tonic changes in discharge produce antinociception. We propose that withdrawals are normally facilitated by noxious stimulation-evoked decreases in OFF and increases in ON cell discharge. The precipitous decrease in OFF cell discharge would synchronize targeted nociceptive circuits in the dorsal horn, leading to a rapidly rising and large magnitude motor reaction. The burst of $\mathrm{ON}$ cell activity facilitates spinal nociceptive circuits so that the time course of ON cell discharge evoked by noxious stimulation anticipates the time course of the motor reaction. Opioid antinociception then results from the suppression of both facilitating cellular responses.

\section{The OFF cell pause is pro-nociceptive}

Our argument that the OFF cell pause is pro-nociceptive is distinct from the obverse idea that OFF cell activity is antinociceptive. The latter was originally proposed to emphasize a role for tonic OFF cell activity in "inhibiting phasic movements" but is not consistent with greater tonic OFF cell activity before withdrawals than before withdrawal failures. The need for a decrease from a high level of activity along with the tight temporal correlation between the onsets of the OFF cell pause and the withdrawal suggest that the OFF cell pause releases spinal withdrawal circuits and thereby synchronizes motor recruitment. Indirect excitation produced by the inhibition of an active inhibitory neuron, termed postinhibitory rebound excitation, plays a crucial role in synchronizing motor responses in many systems (Perkel and Mulloney, 1974; Nusbaum and Beenhakker, 2002). Consistent with this scenario, most OFF cells contain GAD, the synthesizing enzyme for GABA, and spinal projections from RM terminate postsynaptically so that GABAergic OFF cells could directly inhibit as well as mediate disinhibition of dorsal horn neurons (Winkler et al., 2006; Aicher et al., 2012).

\section{The ON cell burst shapes motor withdrawals}

That the magnitudes of ON cell and motor responses are highly correlated is consistent with findings that the pattern of ON cell bursts resembles the pattern of motor force elicited by noxious stimulation in anesthetized rats (Jinks et al., 2004). Accordingly, we pro- 
A

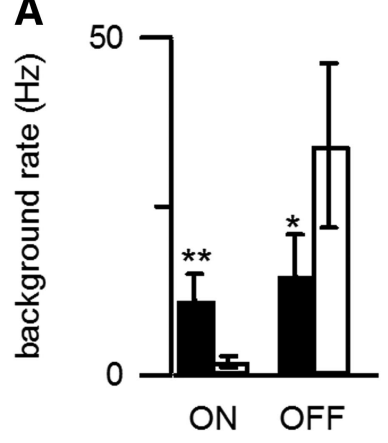

B

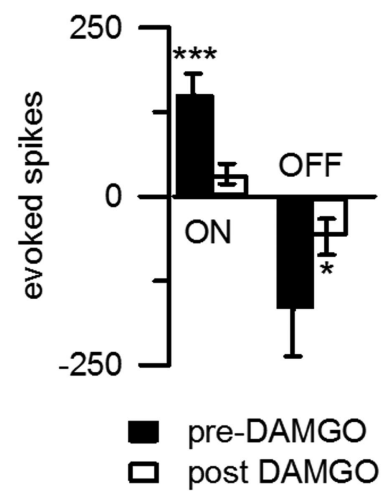

C

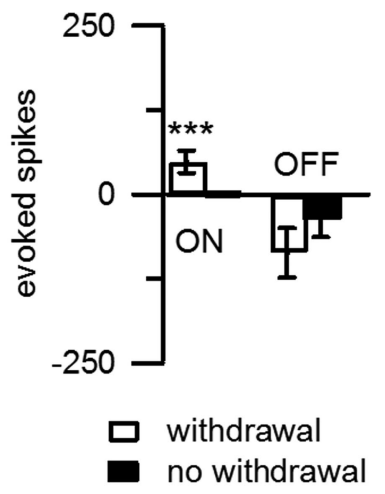

D

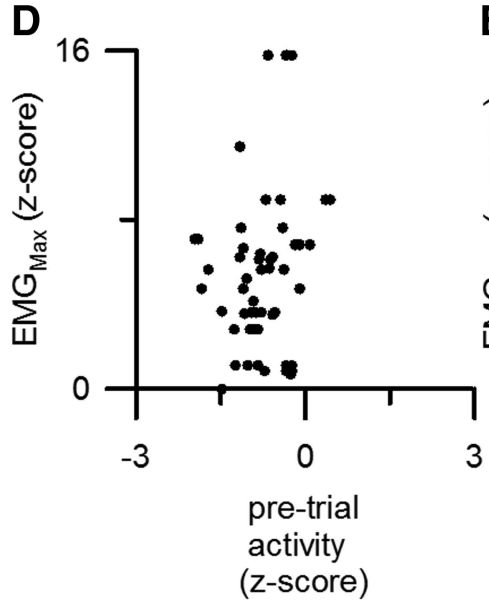

E

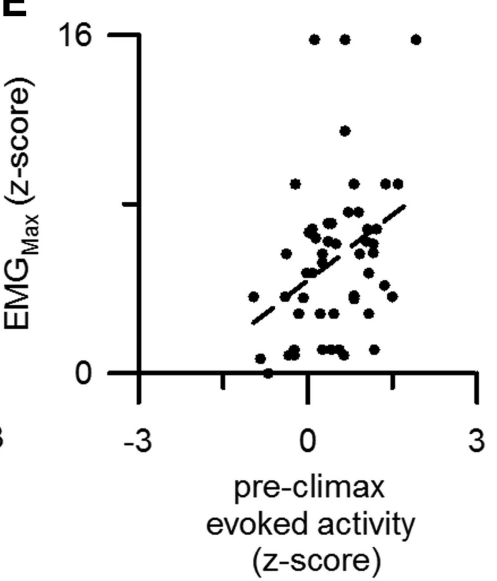

F

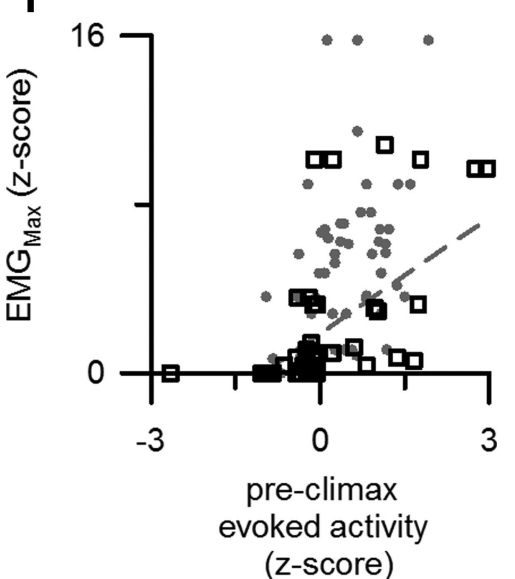

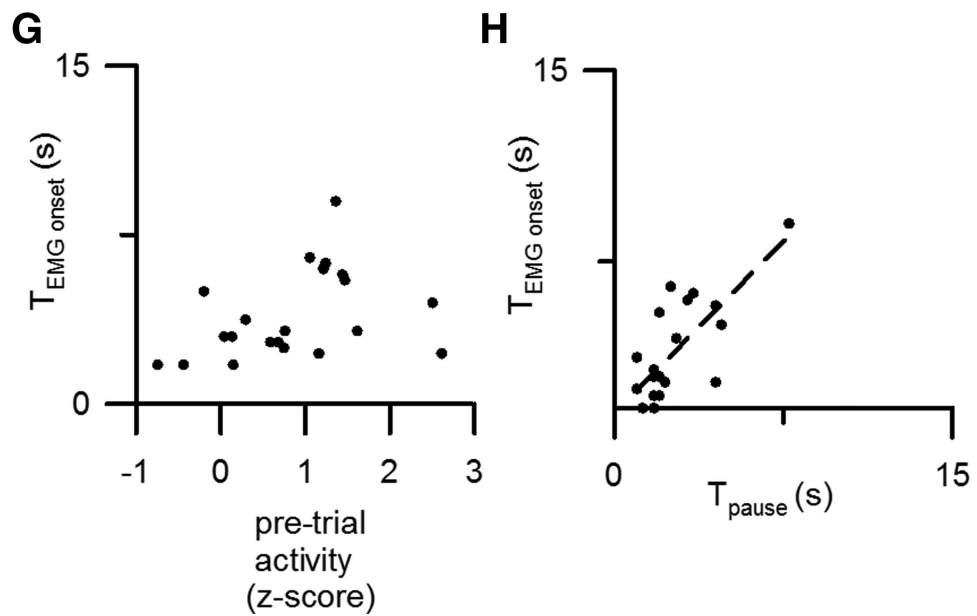

I

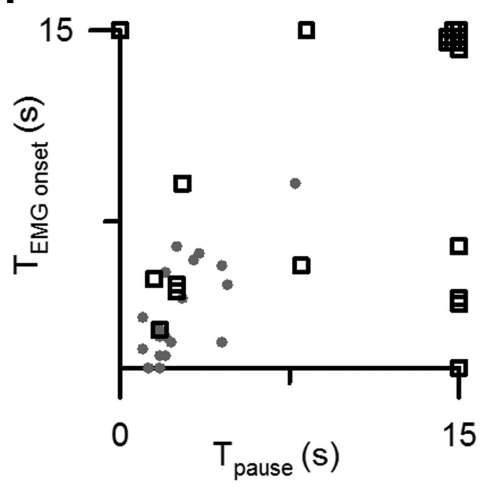

Figure 7. Opioid administration caused changes in the responses of RM cells to noxious stimulation in the lightly anesthetized rat that resemble those observed in the unanesthetized mouse. $A$, $\boldsymbol{B}$, The average firing rates $(\boldsymbol{A})$ and evoked responses $(\boldsymbol{B})$ of RM ON ( 51 trials in 17 cells from 17 rats) and OFF cells ( 22 trials in 9 cells from 9 rats) are shown before and after intracerebroventricular DAMGO administration in the rat. C, After DAMG0 administration, $0 \mathrm{~N}$ cells were responsive only when a withdrawal occurred ( 35 of 51 trials). D, Pretrial $0 \mathrm{~N}$ cell activity was not correlated with peak withdrawal magnitude. $\boldsymbol{E}, \boldsymbol{F}$, The $0 \mathrm{~N}$ cell burst was correlated with maximal EMG amplitude both before $(\boldsymbol{E})$ and after $(\boldsymbol{F})$ DAMGO administration. Symbols are as in Figure 4, $B$ and $C$. $\boldsymbol{G}$, There was no correlation between withdrawal latency and pretrial $0 \mathrm{FF}$ cell activity. $\boldsymbol{H}$, There was a correlation between withdrawal latency and the latency to the $0 \mathrm{FF}$ cell pause. $\boldsymbol{I}, \mathrm{DAMG} 0$ administration disrupted the correlation between withdrawal and OFF cell pause latencies. ${ }^{*} p<0.05 ;{ }^{* *} p<0.01 ;{ }^{* * *} p<0.001$. A-I are from 26 rats and includes data from $170 \mathrm{~N}$ cells and 9 0FF cells.

pose that ON cell activity shapes motor output. ON cell facilitation may be sufficiently effective that a reduction in $\mathrm{ON}$ cell activity alone is antinociceptive. Indeed, supraspinal administration of several nonopioid compounds suppresses evoked ON cell bursts (while depressing the spontaneous discharge of ON and OFF cells) and increases tail flick latency in anesthetized rats (de Novellis et al., 2008, 2012; Maione et al., 2011). As withdrawal magnitudes were not measured in these studies, it is unclear whether magnitudes were de- creased. Nonetheless, the evidence clearly supports the idea that ON cells strongly facilitate spinal withdrawal circuits and that removal of this facilitating influence is enough to greatly attenuate or abolish withdrawals.

The phasic model explains hitherto confusing findings

The tonic model predicts that no change in nociceptive responsiveness would follow manipulations that alter evoked ON and 
OFF cell responses without changing spontaneous activity of these cells. Yet, systemic administration of a cannabinoid receptor agonist suppresses $\mathrm{ON}$ and $\mathrm{OFF}$ cell responses to noxious stimulation and causes antinociception without affecting tonic ON or OFF cell discharge (Meng et al., 1998). Additionally, microinjection of kynurenate into RM of anesthetized rats suppresses tonic and phasic ON cell activity without changing OFF cell firing (Heinricher and McGaraughty, 1998). As predicted by our model, there is no effect on tail flick latency, but the magnitude of evoked paw withdrawals is decreased (Jinks et al., 2007). The tonic model also predicts that tonic elevation in OFF cell discharge during slow-wave sleep (Leung and Mason, 1999) will produce a state of antinociception. However, during sleep and as predicted by the phasic model, noxious stimulation elicits strong phasic responses in RM cells along with robust withdrawals (Mason et al., 2001).

Mediation of RM nociceptive modulation by the ON cell burst and OFF cell pause theoretically allows for nuanced changes in nociceptive responses. For example, facilitation of the ON cell burst alone may produce large-magnitude withdrawals, whereas augmentation of the evoked decrease in OFF cell discharge may make withdrawals brisker. In this way, various combinations of $\mathrm{ON}$ and OFF cell firing patterns may produce a range of effects, each ideally suited to a different circumstance.

\section{RM may modulate nociception only when necessary}

Changes in the phasic responses of ON and OFF cells to noxious stimulation are sufficient to explain RM's contributions to nociceptive modulation. Yet, the ongoing activity of $\mathrm{ON}$ and $\mathrm{OFF}$ cells may also modulate nociception. Insufficient information is currently available to judge this issue. Alternatively, RM's role in nociceptive modulation may be restricted to phasic responses and therefore to the periwithdrawal period. In this case, the tonic discharge of RM cells may contribute to non-nociceptive functions when no noxious stimulus is present. RM cell activity may modulate breathing rate, ensuring adequate respiration during active movements (Hellman et al., 2007). RM cells may also regulate sensory input from the bladder, ensuring that sleep is not interrupted by bladder filling (Baez et al., 2005). These functions are examples of somatomotor modulation and are not drastically different from nociceptive modulation. In sum, we propose that RM modulates somatomotor processing primarily of innocuous somatosensory inputs that occur every minute of every day but also of nociceptive inputs that occur far more rarely.

\section{References}

Aicher SA, Hermes SM, Whittier KL, Hegarty DM (2012) Descending projections from the rostral ventromedial medulla (RVM) to trigeminal and spinal dorsal horns are morphologically and neurochemically distinct. J Chem Neuroanat 43:103-111.

Azami J, Llewelyn MB, Roberts MH (1982) The contribution of nucleus reticularis paragigantocellularis and nucleus raphe magnus to the analgesia produced by systemically administered morphine, investigated with the microinjection technique. Pain 12:229-246.

Baez MA, Brink TS, Mason P (2005) Roles for pain modulatory cells during micturition and continence. 25:384-394.

Barbaro NM, Heinricher MM, Fields HL (1986) Putative pain modulating neurons in the rostral ventral medulla: reflex-related activity predicts effects of morphine. Brain Res 366:203-210.

Brink TS, Hellman KM, Lambert AM, Mason P (2006) Raphe magnus neurons help protect reactions to visceral pain from interruption by cutaneous pain. J Neurophysiol 96:3423-3432.

Brodal A, Taber E, Walberg F (1960) The raphe nuclei of the brain stem in the cat. II. Efferent connections. J Comp Neurol 114:239-259.

Chaillet P, Marçais-Collado H, Costentin J (1983) Catatonic or hypotonic immobility induced in mice by intracerebroventricular injection of mu or kappa opioid receptor agonists as well as enkephalins or inhibitors of their degradation. Life Sci 33:2105-2111.

Dahlstroem A, Fuxe K (1964) Evidence for the existence of monoamine neurons in the central nervous system. Acta Physiol Scand Suppl 232:1-55.

da Silva GR, Rocha e Silva M (1971) Catatonia induced in the rabbit by intracerebral injection of bradykinin and morphine. Eur J Pharmacol 15:180-186.

de Novellis V, Palazzo E, Rossi F, De Petrocellis L, Petrosino S, Guida F, Luongo L, Migliozzi A, Cristino L, Marabese I, Starowicz K, Di Marzo V, Maione S (2008) The analgesic effect of $\mathrm{N}$-arachidonoyl-serotonin, a FAAH inhibitor and TRPV1 receptor antagonist, associated with changes in rostral ventromedial medulla and locus coeruleus cell activity in rats. Neuropharmacology 55:1105-1113.

de Novellis V, Luongo L, Guida F, Cristino L, Palazzo E, Russo R, Marabese I, D’Agostino G, Calignano A, Rossi F, Di Marzo V, Maione S (2012) Effects of intra-ventrolateral periaqueductal grey palmitoylethanolamide on thermoceptive threshold and rostral ventromedial medulla cell activity. Eur J Pharmacol 676:41-50.

Dickenson AH, Oliveras JL, Besson JM (1979) Role of the nucleus raphe magnus in opiate analgesia as studied by the microinjection technique in the rat. Brain Res 170:95-111.

Fang FG, Haws CM, Drasner K, Williamson A, Fields HL (1989) Opioid peptides (DAGO-enkephalin, dynorphin A(1-13), BAM 22P) microinjected into the rat brainstem: comparison of their antinociceptive effect and their effect on neuronal firing in the rostral ventromedial medulla. Brain Res 501:116-128.

Fields HL, Bry J, Hentall I, Zorman G (1983a) The activity of neurons in the rostral medulla of the rat during withdrawal from noxious heat. J Neurosci 3:2545-2552.

Fields HL, Vanegas H, Hentall ID, Zorman G (1983b) Evidence that disinhibition of brain stem neurones contributes to morphine analgesia. Nature 306:684-686.

Fields HL, Basbaum AI, Clanton CH, Anderson SD (1977) Nucleus raphe magnus inhibition of spinal cord dorsal horn neurons. Brain Res 126: 441-453.

Gao K, Chen DO, Genzen JR, Mason P (1998) Activation of serotonergic neurons in the raphe magnus is not necessary for morphine analgesia. J Neurosci 18:1860-1868.

Gebhart GF, Sandkühler J, Thalhammer JG, Zimmermann M (1983) Quantitative comparison of inhibition in spinal cord of nociceptive information by stimulation in periaqueductal gray or nucleus raphe magnus of the cat. J Neurophysiol 50:1433-1445.

Gilbert AK, Franklin KB (2002) The role of descending fibers from the rostral ventromedial medulla in opioid analgesia in rats. Eur J Pharmacol 449:75-84.

Grahn DA, Heller HC (1989) Activity of most rostral ventromedial medulla neurons reflect EEG/EMG pattern changes. Am J Physiol 257:R1496R1505.

Heinricher MM, McGaraughty S (1998) Analysis of excitatory amino acid transmission within the rostral ventromedial medulla: implications for circuitry. Pain 75:247-255.

Heinricher MM, Rosenfeld JP (1985) Microinjection of morphine into nucleus reticularis paragigantocellularis of the rat: suppression of noxious-evoked activity of nucleus raphe magnus neurons. Brain Res 359:388-391.

Heinricher MM, Barbaro NM, Fields HL (1989) Putative nociceptive modulating neurons in the rostral ventromedial medulla of the rat: firing of on- and off-cells is related to nociceptive responsiveness. Somatosens Mot Res 6:427-439.

Heinricher MM, Morgan MM, Fields HL (1992) Direct and indirect actions of morphine on medullary neurons that modulate nociception. Neuroscience 48:533-543.

Heinricher MM, Morgan MM, Tortorici V, Fields HL (1994) Disinhibition of off-cells and antinociception produced by an opioid action within the rostral ventromedial medulla. Neuroscience 63:279-288.

Hellman KM, Brink TS, Mason P (2007) Activity of murine raphe magnus cells predicts tachypnea and on-going nociceptive responsiveness. J Neurophysiol 98:3121-3133.

Hellman K, Hernandez P, Park A, Abel T (2010) Genetic evidence for a role for protein kinase A in the maintenance of sleep and thalamocortical oscillations. Sleep 33:19-28. 
Jinks SL, Carstens E, Antognini JF (2004) Isoflurane differentially modulates medullary on and off neurons while suppressing hind-limb motor withdrawals. Anesthesiology 100:1224-1234.

Jinks SL, Carstens EE, Antognini JF (2007) Glutamate receptor blockade in the rostral ventromedial medulla reduces the force of multisegmental motor responses to supramaximal noxious stimuli. Neurosci Lett 426:175-180.

Leung CG, Mason P (1995) Effects of isoflurane concentration on the activity of pontomedullary raphe and medial reticular neurons in the rat. Brain Res 699:71-82.

Leung CG, Mason P (1998) Physiological survey of medullary raphe and magnocellular reticular neurons in the anesthetized rat. J Neurophysiol 80:1630-1646.

Leung CG, Mason P (1999) Physiological properties of raphe magnus neurons during sleep and waking. J Neurophysiol 81:584-595.

Maione S, Piscitelli F, Gatta L, Vita D, De Petrocellis L, Palazzo E, de Novellis V, Di Marzo V (2011) Non-psychoactive cannabinoids modulate the descending pathway of antinociception in anaesthetized rats through several mechanisms of action. Br J Pharmacol 162:584-596.

Martin G, Montagne-Clavel J, Olivéras JL (1992) Involvement of ventromedial medulla "multimodal, multireceptive" neurons in opiate spinal descending control system: a single-unit study of the effect of morphine in the awake, freely moving rat. J Neurosci 12:1511-1522.

Mason P (2005a) Deconstructing endogenous pain modulations. J Neurophysiol 94:1659-1663.

Mason P (2005b) Ventromedial medulla: pain modulation and beyond. J Comp Neurol 493:2-8.

Mason P, Escobedo I, Burgin C, Bergan J, Lee JH, Last EJ, Holub AL (2001) Nociceptive responsiveness during slow-wave sleep and waking in the rat. Sleep 24:32-38.

McGaraughty S, Reinis S, Tsoukatos J (1993) Two distinct unit activity responses to morphine in the rostral ventromedial medulla of awake rats. Brain Res 604:331-333.
Meng ID, Manning BH, Martin WJ, Fields HL (1998) An analgesia circuit activated by cannabinoids. Nature 395:381-383.

Nusbaum MP, Beenhakker MP (2002) A small-systems approach to motor pattern generation. Nature 417:343-350.

Perkel DH, Mulloney B (1974) Motor pattern production in reciprocally inhibitory neurons exhibiting postinhibitory rebound. Science 185: 181-183.

Pert CB, Snyder SH (1973) Opiate receptor: demonstration in nervous tissue. Science 179:1011-1014.

Pogosyan A, Kühn AA, Trottenberg T, Schneider GH, Kupsch A, Brown P (2006) Elevations in local gamma activity are accompanied by changes in the firing rate and information coding capacity of neurons in the region of the subthalamic nucleus in Parkinson's disease. Exp Neurol 202:271-279.

Porreca F, Ossipov MH, Gebhart GF (2002) Chronic pain and medullary descending facilitation. Trends Neurosci 25:319-325.

Reynolds DV (1969) Surgery in the rat during electrical analgesia induced by focal brain stimulation. Science 164:444-445.

Shannon CE, Weaver W (1949) The mathematical theory of communication. Urbana, IL: University of Illinois.

Toda K (1982) Responses of raphe magnus neurons to systemic morphine in rats. Brain Res Bull 8:101-103.

VanderHorst VG, Ulfhake B (2006) The organization of the brainstem and spinal cord of the mouse: relationships between monoaminergic, cholinergic, and spinal projection systems. J Chem Neuroanat 31:2-36.

Winkler CW, Hermes SM, Chavkin CI, Drake CT, Morrison SF, Aicher SA (2006) Kappa opioid receptor (KOR) and GAD67 immunoreactivity are found in OFF and NEUTRAL cells in the rostral ventromedial medulla. J Neurophysiol 96:3465-3473.

Winters WD, Hance AJ, Cadd GG, Quam DD, Benthuysen JL (1988) Ketamine- and morphine-induced analgesia and catalepsy. I. Tolerance, cross-tolerance, potentiation, residual morphine levels and naloxone action in the rat. J Pharmacol Exp Ther 244:51-57. 